\title{
Ossifying Fibroma of the Mandible - Case Report and Literature Review
}

\author{
Deliverska, E., M. Rubiev
}

\begin{abstract}
Background: Ossifying fibroma $(\mathrm{OF})$ is a rare neoplasm of the craniofacial skeleton. It can affect all ages, although it is discovered mostly in the second to fourth decade of life. It occurs predominantly in females and most common site is the mandible (molar and premolar region). OF is a benign tumor with usually slow and asymptomatic development. In some cases described as "juvenile" more rapid and aggressive behavior is observed. Materials and Methods: We report a case of 26-year-old woman with OF of the mandible that was presented to our department. The patient was referred to us for clinical evaluation, diagnosis and treatment of an asymptomatic, mixed radiolucent/radiopaque lesion from second left madibular incisor to the first left mandibular premolar. A decision for excisional biopsy was taken. Results and Conclusion: The patient underwent operation under local anesthesia - enucleation of the tumor and peripheral osteotomy, the histopathological findings were conclusive with $\mathrm{OF}$. No recurrence was seen after 2 years follow up.
\end{abstract}

Keywords: Ossifying fibroma, Maxillofacial, Mandible

\section{Introduction}

Ossifying fibroma (OF) is a rare benign tumor of the jawbones consisting of fibrous connective tissue with sites of calcifications resembling bone and/or cement $(12,26)$. It is agreed that the terms ossifying fibroma, cemento-ossifying fibroma and cementifying fibroma describe the same pathologic process $(13,15)$. According to $\mathrm{WHO}$, OF belongs to fibro-osseous lesions along with fibrous dysplasia (FD), florid osseous dysplasia and focal osseous dysplasia $(13,15)$.

OF is further divided into conventional and juvenile (JOF) subtypes. The histological characteristics of both fibrous tissue and bony material may vary in wide range. Woven and/or lamellar bone and/or cementoid could be observed in $\mathrm{COF}$ and the structure of the stroma may vary from highly cellular to prominently vascular( $(13,15)$. On the other hand the JOF has two well defined subtypes based on the histological findings - trabecular (JTOF) and psammomatoid (JPOF). The most distinctive feature of the JPOF is the formation of "psammomatoid bodies" spherical calcified ossicles containing osteocytes, with basophilic center distributed in dense cellular fibrous stroma.(13) The JTOF forms immature irregulartrabeculae with osteoidseams.

Although the data differ most authors report significant female predilection of OF. It can be found in any age from 3 to 84 (15), but most often it occurs in second to fourth decade of life. COF has highest incidence in the mandible (88\% according to Kaplan et al. (10) with a definite predilection to the premolars and molars region. JPOF is most frequently found in the sinonasal and orbital bones and the JTOF predominantly affects the jaws with a preference to the maxilla(10). There are occasional reports for $\mathrm{OF}$ found in other bones, such as the calvaria (Sze Yin Lam et al reports a case of an occipital OF), frontal, sphenoid, temporal bones and the base of the skull $(6,7,12,17)$.

The pathogenesis of this lesion is still uncertain. There are authors that describe only some of those lesions as neoplastic and other as reactive in nature (15). Most researchers adopt the theory that the COF arises from the periodontal ligament which contains pluripotential cells capable of forming bone, cement and fibrous tissue, whereas the etiology of JOF is suggested to be from overproductionof the myxofibrous cellular stroma normally involved inthe growth of the septa in the paranasal sinuses as they enlargeand pneumatize $(13,15)$.

The radiographic presentation of OF varies from radiolucent (small lesions) trough mixed radiolucent/radiopaque to completely radiopaque with thin radiolucent rim in more mature lesions. It usually appears as round lesion with welldemarcated borders often with osteosclerosis. Big lesions may represent as multilocular and in some cases of JOF the borders may be more difficult to determine, which correlates with the more aggressive behavior of those tumors. The lesion could dislocate the roots of the adjacent teeth or in some cases to cause root resorption.

OF usually has slow, asymptomatic growth. The most commonly observed clinical symptom is painless enlargement of the affected bone, which leads to facial asymmetry. Despite the slow growth some lesions could reach huge dimensions. Big lesions could perforate the cortical plate and in such cases crepitation may be presented. Pain is also a common symptom. Inflammation and/or hemorrhage are rare and secondary clinical presentations of this tumor.

Being a benign tumor COF could be treated successfully with enucleation and only larger lesions enforce resection with a subsequent reconstruction usually with iliac or fibular auto transplant, whereas JOF, because of its aggressive growth, shows high recurrence rate after enucleation, which imposes en-bloc resection in healthy borders to be the treatment in choice for those lesions. $(8,15,26)$

In rare cases $\mathrm{OF}$ could occur in association with other bone lesions such as Aneurysmal Bone Cyst (ABC), Central Giant Cell Granuloma (CGCG) and Complex odontoma or it could develop as part of the hyperparathyroidism-jawtumour (HPT-JT) syndrome. Triantafillidou et al presented a case of $\mathrm{OF}$ associated with a recurred $\mathrm{ABC}$ previously treated by curettage. CGCG of the jaws is a rare benign lesion 


\section{International Journal of Science and Research (IJSR) \\ ISSN (Online): 2319-7064}

Index Copernicus Value (2013): 6.14 | Impact Factor (2014): 5.611

containing osteoclast-like giant cells scattered in a cellularfibrovascular stroma $(15,26)$. Kaplan et al reported three cases of combined CGCG-COF lesions. Matsuo et al observed a case of OF that occurred in the place of a removed complex odontoma. Very rarely synchronous development of multiple OFs not associated with HPT-JT syndrome could be observed (Akcam et al report such case).

Differential Diagnosis of OF is not always easy and should be made based on the thorough clinical and radiographic examination and histopatological findings. Osteoblastoma, fibrous dysplasia, central giant cell granuloma,ameloblastoma, ameloblastic fibroma, ameloblasticfibro-odontoma,

adenomatoidodontogenictumor, aneurismal bone cyst and calcifying odontogenic cyst could resemble OF in their clinical and radiographic representation and should be considered in the differential diagnosis $(1,2,9,11,14,18)$. Chang et al.(4) observed two cases of OFs misdiagnosed as radicular cyst and adenomatoidodontogenic tumor in which the first diagnosis was based only on the radiographs. Some authors suggests that peritrabecular clefting may be an important additional microscopic diagnostic criterionto diagnose and differentiateFD from OF.(15, 20, 25, 26)

\section{Case Report}

We present a 26 years old female with OFof the mandible. The patient was referred to us from her general dentist for clinical evaluation, diagnosis and treatment of an asymptomatic, mixed radiolucent/radiopaque lesion from second left madibular incisor to the first left mandibular premolar which was revealed on a routine OPG. On clinical examination the patient was without subjective complaints. There was no bone deformation or pain and crepitation on palpation.Radiografic imaging showed radiolucent/radioopaque lesion on left side side of lower jaw, with well-defined borders and no resorption of roots of teeth 32,33, unilocular in appearance (Fig.1).OF and calcifying odontogenic cyst were considered as possible, based on the clinical examination and the radiographic findings. Decision for excisional biopsy was taken and the patient was operated under local anaesthesia. The tumour mass was removed through an intraoral approach and curettage with peripheral ostectomy with preservation of the continuity of the mandible with at least a $2 \mathrm{~mm}$ margin was performed. Although the vitality pulp test showed that teeth 32,33 are vital we decided to perform endodontic treatment prior the operation. The patient recovered from the operation normally. The histological findings were consistent with OF (Fig 2).

\section{Result}

At the 2-year clinical and radiological follow up there was no sign of recurrence. The postoperative defect is almost fully reconstructed (Fig. 3).

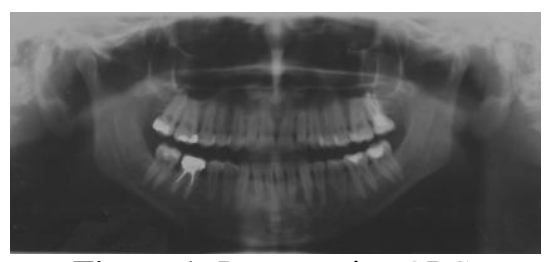

Figure 1: Preoperative OPG

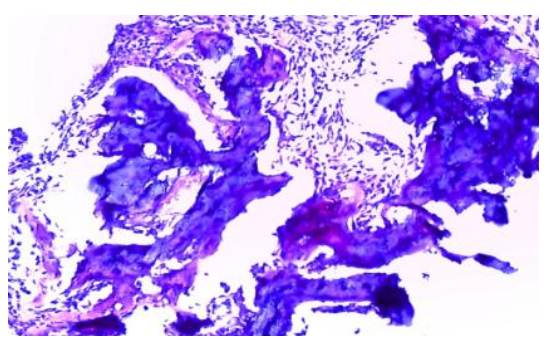

Figure 2: Histological image

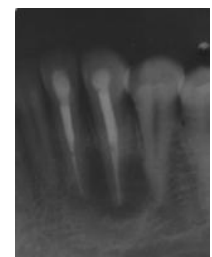

Figure 3: 2 year post operation

\section{Discussion}

Ossifying fibroma of craniofacial bones is a benign neoplasm, mainly composed of 2 components: fibrous stroma and bone elements that show various degrees of maturation. The stroma consists of fibroblasts and colagenous fibers. Bone elements include mineralized bodies (ossicles), osteoids, fiber bone (woven bone), and mature bone (lamellar bone)(26)

Ossicles connect to form bone trabeculae that usually is surrounded by osteoblasts and occasionally by osteoclasts. Rounded cementum-like masses may be present either alone or together with the trabeculae $(3,6,15,17)$. Because of the variation in the configuration of these calcified deposits, such tumors have been referred to as both ossifying and cementifying fibroma $(15,16,22,23,31,32)$.

Marx and Stern(15)have stated that OF occurs frequently in the jaws, probably because these lesions are related to an extensive mesenchymal cellular induction into bone and cementum, required in odontogenesis. Therefore, when there is an error in the tissue induction process, an OF may be developed in the jaws. It is thought that some fibro-osseous lesions arise from the periodontal ligament, which contains pluripotential cells capable of forming cementum, bone, and fibrous tissue $(3,15,16,31)$. The neoplastic nature of $\mathrm{OF}$ is attributed to the fact that large lesions exhibit aggressive behavior, producing significant osseous destruction. Additionally, recurrences, though rare, have been described in some cases of OF. Others categorize this lesion as a localized dysplastic process in which bone metabolism is altered $(22,29,31)$.

By either method of treatment, the recurrence rate for OF is low $(15,23)$.For aggressive tumors that show rapid 


\section{International Journal of Science and Research (IJSR) \\ ISSN (Online): 2319-7064}

Index Copernicus Value (2013): 6.14 | Impact Factor (2014): 5.611

enlargement, the recurrence rate is estimated to be $20 \%$ $25 \%$. Such tumors will usually require radical resection. It is advisable that the clinician follow these patients with yearly examination. $(3,4,5,8,15,31,32)$ The recurrence rate in the present patients $(14 \%)$ is in accordance to that estimated in literature.

In any case, the decision on whether to enucleate or resect radically, depends on involvement of the inferior border of the mandible and the spread of the lesion in the soft tissues or in the maxillary sinus and nasal cavity $(15,21,28,30)$. Both surgical methods of treatment for OF (conservative or radical) are acceptable by most authors in the Englishlanguage literature during the past 30 years, as reported in their clinical studies(3,4,16,21,24,30,31,32). Conservative surgery was addressed for small lesions, whereas larger lesions required radical surgery. The above surgical protocol was also applied for the patient of the present study.

Differential diagnosis between OF and other fibro- osseous lesions sometimes is difficult, because all of these lesions may exhibit similar clinical, radiographic, and histologic features(23,28,31,32,27).Distinguishing between fibrous dysplasia (FD) and OF is the primary differential diagnostic challenge. The most helpful feature distinguishing FD and $\mathrm{OF}$ is the well circumscribed appearance of $\mathrm{OF}$ in radiography and the ease with which it can be separated from normal bone in surgery. Histologically, FD is reported to contain only woven bone, without evidence of osteoblastic rimming of bone. The presence of mature lamellar bone in histology is believed to be characteristic of $\mathrm{OF}(3,15,23,32)$. If the OF occurs around tooth roots, it may also resemble a cementoblastoma or florid cemento-osseous dysplasia. These rare lesions may be distinguished from an OF by their radiographic appearance. The cementoblastoma is fused to the root of the involved tooth, and florid cementoosseous dysplasia exhibits not 1 but severalsclerotic densities in the alveolar bone of one or both jaws $(15,24)$

Conclusion. OF is a benign fibro-osseous tumor, most commonly found in the jaws, especially in the mandible. Buccal or lingual cortical bone swelling or expansion is the most common clinical feature. The radiographic picture of $\mathrm{OF}$ is more frequently a well defined mixed lesion (radiolucent/radiopaque). Most OFs can be treated by conservative surgical excision(23). Although the recurrence rate of this tumor seems to be extremely low, the patients must be followed up carefully, particularly because the tumor has proved to be aggressive, recurring sometimes after conservative surgical procedures.

\section{References}

[1] Buraczewski J, Dabska M. Pathogenesis of aneurysmal bone cyst. Relationship between the aneurysmal bone cyst and fibrous dysplasia of bone. Cancer 1971;28:597604.

[2] El Deeb M, Sedano HO, Waite DE. Aneurysmal bone cyst of the jaws. Report of a case associated with fibrous dysplasia and review of the literature. Int J Oral Surg 1980;9:301-11.

[3] Eversole LR, Leider AS, Nelson K. Ossifying fibroma: a clinicopathologic study of sixty-four cases. Oral Surg
Oral Med Oral Pathol Oral Radiol Endod 1985;60:50511.

[4] Chang CC, Hung HY, Chang JY, et al. Central ossifying fibroma: a clinicopathologic study of 28 cases. J Formos Med Assoc 2008;107:288-94.

[5] Cheng C, Takahashi $\mathrm{H}$, Yao $\mathrm{K}$, et al. Cementoossifying fibroma of maxillary and sphenoid sinuses: case report and literature review. Acta Otolaryngol Suppl

[6] Fu YS, Perzin KH. Nonepithelial tumors of the nasal cavity, paranasal sinuses, and nasopharynx. A clinicopathologic study. II. Osseous and fibro-osseous lesions, including osteoma, fibrous dysplasia, ossifying fibroma, osteoblastoma, giant cell tumor, and osteosarcoma. Cancer 1974;33:1289-305.

[7] Fujimoto Y, Katoh M, Miyata M, Kawai T, Saito K, Morita M. Cystic cemento-ossifying fibroma of the ethmoidal cells (a case report). J Laryngol Otol 1987;101:946-52.

[8] Gurol M, Uckan S, Guler N, Yatmaz PI. Surgical and reconstructive treatment of a large ossifying fibroma of the mandible in a retrognathic patient. J Oral Maxillofac Surg 2001;59: 1097-100.

[9] Johnson LC, Yousefi M, Vinh TN, Heffiner DK, Hymans VJ, Hartman KS. Juvenile active ossifying fibroma, its nature dynamics and origin. Acta Otolaryngol Suppl 1991;488:1-40.

[10] Kaplan I, Manor I, Yahalom R, et al. Central giant cell granuloma associated with central ossifying fibroma of the jaws: a clinicopathologic study. Oral Surg Oral Med Oral Pathol Oral Radiol Endod 2007;103:e35-41.

[11] Keles B, Duran M, Uyar Y, Azimov A, Demirkan A, Esen HH. Juvenile ossifying fibroma of the mandible: a case report. J Oral Maxillofac Res 2010;1:e5;1-7.

[12] Levine PA, Wiggins R, Archibald RW, Britt R. Ossifying fibroma of the head and neck: involvement of the temporal bone- and unusual and challenging site. Laryngoscope 1981;91:720-5.

[13] Macdonald-Jankowski DS. Fibro-osseous lesions of the face and jaws. Clin Radiol 2004;59:11-252002;547:11822.

[14] Martinez V, Sissons HA. Aneurysmal bone cyst. A review of 123 cases including primary lesions and those secondary to other bone pathology. Cancer 1988;61:2291-304.

[15] Marx RE, Stern D. Oral and maxillofacial pathology. A rationale for diagnosis and treatment. Chicago: Quintessence; 2002. p. 789-95.

[16] Mintz S, Velez I. Central ossifying fibroma: an analysis of 20 cases and review of the literature. Quintessence Int 2007; 38:221-7.

[17] Nakagawa K, Takasato Y, Ito Y, Yamada K. Ossifying fibroma involving the paranasal sinuses, orbit, and anterior cranial fossa: case report. Neurosurgery 1995;36:1192-5.

[18]Penfold CN, Mccullagh P, Eveson JW, Ramsay A. Giant cell lesions complicating fibro-osseous conditions of the jaws. Int J Oral Maxillofac Surg 1993;22:158-62

[19] Padwa BL, Denhart BC, Kaban LB. Aneurysmal bone cyst- "plus": a report of three cases. J Oral Maxillofac Surg 1997; 55:1144-52.

[20] Sanchis JM, Peñarrocha M, Balaguer JM, Camacho F. Cemento- ossifying mandibular fibroma: a presentation 


\section{International Journal of Science and Research (IJSR) \\ ISSN (Online): 2319-7064}

Index Copernicus Value (2013): 6.14 | Impact Factor (2014): 5.611

of two cases and review of the literature. Med Oral 2004;9:69-73.

[21] Sciubba JJ, Younai F. Ossifying fibroma of the mandible and maxilla: review of 18 cases. J Oral Pathol Med 1989;18:315-21.

[22] Smith SF, Newman L, Walker DM, Papadopoulos H. Juvenile aggressive psammomatoid ossifying fibroma: an interesting, challenging, and unusual case report and review of the literature. J Oral Maxillofac Surg 2009;67:200-6.

[23] Stewart JCB. Benign nonodontogenic tumors. In: Regezi JA, Sciubba JJ, editors. Oral pathology. Clinical pathologic correla- tions. 3rd ed. Philadelphia: Saunders; 1999: p. 357-60.

[24] Su L, Weathers DR, Waldron CA. Distinguishing features of focal cemento-osseous dysplasias and cemento-ossifying fibro- mas: I. A pathologic spectrum of 316 cases. Oral Surg Oral Med, Oral Pathol Oral Radiol Endod 1997;84:301-9.

[25] Thankappan S, Nair S, Thomas V, Sharafundeen KP. Psammomatoid and trabecular variants of juvenile ossifying fibroma - two case reports. Indian J Radiol Imaging 2009;19:116-9.

[26] Triantafillidou K,Venetis G,Karakinaris, G, Iordanidis, F.Ossifying fibroma of the jaws: a clinical study of 14 cases andreview of the literature; Oral Surg Oral Med OralPathol Oral Radiol 2012; 114:193-199

[27] Trent C, Byl FM. Aneurysmal bone cyst of the mandible. Ann Otol Rhinol Laryngol 1993;102:917-24.

[28] Vegas-Bustamante E, Gargallo-Albiol J, Berini-Aytés L, Gay Escoda C. Benign fibro-osseous lesions of the maxillas: analysis of 11 cases. Med Oral Patol Oral Cir Bucal 2008;13:E653-6.

[29]Zachariades N, Vairaktaris E, Papanicolaou S, Triantafyllou D, Papavassiliou D, Mezitis M. Ossifying fibroma of the jaws. Review of the literature and report of 16 cases. Int J Oral Surg 1984;13:1-6.

[30]Zama M, Gallo S, Santechia L, Bertozzi E, De Stefano C. Juvenile active ossifying fibroma with massive involvement of the mandible. Plast Recontr Surg 2004;113:970-4.

[31] Waldron CA. Fibro-osseous lesions of the jaws. J Oral Maxillo- fac Surg 1993;51:828-35. Review.

[32] Wojno KJ, Mccarthy EF. Fibro-osseous lesions of the face and skull with aneurysmal bone cyst formation. Skeletal Radiol 1994;23:15-8. 